\title{
ARTICLE \\ Blockade of muscarinic acetylcholine receptors facilitates motivated behaviour and rescues a model of antipsychotic- induced amotivation
}

\author{
Jonathan M. Hailwood (D) ${ }^{1}$, Christopher J. Heath ${ }^{2}$, Benjamin U. Phillips ${ }^{1}$, Trevor W. Robbins ${ }^{1}$, Lisa M. Saksida ${ }^{3,4}$ and Timothy J. Bussey ${ }^{1,3,4}$
}

\begin{abstract}
Disruptions to motivated behaviour are a highly prevalent and severe symptom in a number of neuropsychiatric and neurodegenerative disorders. Current treatment options for these disorders have little or no effect upon motivational impairments. We assessed the contribution of muscarinic acetylcholine receptors to motivated behaviour in mice, as a novel pharmacological target for motivational impairments. Touchscreen progressive ratio (PR) performance was facilitated by the nonselective muscarinic receptor antagonist scopolamine as well as the more subtype-selective antagonists biperiden (M1) and tropicamide (M4). However, scopolamine and tropicamide also produced increases in non-specific activity levels, whereas biperiden did not. A series of control tests suggests the effects of the mAChR antagonists were sensitive to changes in reward value and not driven by changes in satiety, motor fatigue, appetite or perseveration. Subsequently, a sub-effective dose of biperiden was able to facilitate the effects of amphetamine upon PR performance, suggesting an ability to enhance dopaminergic function. Both biperiden and scopolamine were also able to reverse a haloperidol-induced deficit in PR performance, however only biperiden was able to rescue the deficit in effort-related choice (ERC) performance. Taken together, these data suggest that the M1 mAChR may be a novel target for the pharmacological enhancement of effort exertion and consequent rescue of motivational impairments. Conversely, M4 receptors may inadvertently modulate effort exertion through regulation of general locomotor activity levels.
\end{abstract}

Neuropsychopharmacology (2019) 44:1068-1075; https://doi.org/10.1038/s41386-018-0281-8

\section{INTRODUCTION}

Successful initiation and maintenance of goal-directed motivated behaviour is crucial to everyday functioning. Impairments in motivated behaviour, or amotivation, is highly prevalent in schizophrenia [1] and neurodegenerative diseases [2]. Patients experiencing amotivation as part of their symptom profile are often those with the most reduced functional outcomes as indicated by poorer quality of life and increased caregiver burden $[3,4]$. However, current treatment approaches have little effect upon the symptoms of apathy [5]. Furthermore, there is some evidence that dopamine receptor antagonists, used as typical antipsychotic treatments, may exacerbate amotivation [6].

Attempts to operationalise motivation for preclinical study have divided motivated behaviour into a number of dimensions [7], which include activational processes [8,9]. Activational processes can be probed through studying the exertion of effort for appetitive reward [7]. One of the most widely used assays for studying activational motivated behaviour is the progressive ratio (PR) schedule of reinforcement [10]. PR schedules test the ability of an organism to maintain operant responding for reward under increasing work requirements. PR performance is highly dependent on intact nucleus accumbens dopamine (DA) function [11, 12] and increasing DA neurotransmission through administration of psychostimulants facilitates PR performance [13]. PR performance can also be facilitated via nondopaminergic compounds including those that act upon the serotonergic and adenosinergic systems $[14,15]$. Studies have also investigated the behavioural pharmacology of effort-related choice (ERC) behaviour [16]. ERC assays probe the ability of an organism to select between the performance of perform high-effort actions to obtain a valued reward or lower-effort actions for less valued rewards [16]. Psychostimulants and numerous other compounds have been shown to reverse pharmacologically induced deficits in ERC performance [16, 17]

Consistent with the preclinical research, the psychostimulants amphetamine and methylphenidate have been reported to have some efficacy in reducing motivational impairments in clinical populations [18, 19]. However, these compounds have limited applicability in certain clinical populations due to abuse potential and possible exacerbation of psychotic symptoms [20]. Identification of compounds that indirectly modulate DA function may offer a viable alternative therapeutic approach.

A powerful modulator of DA signalling is the cholinergic system, which consists of nicotinic (nAChRs) and muscarinic (mAChRs) acetylcholine receptors. $\mathrm{mAChRs}$ consist of five receptor subtypes [M1-M5, [21]]. Numerous studies have shown that mAChRs can bidirectionally modulate DA-dependant behaviours. The behavioural effects of amphetamine are further enhanced by mAChR

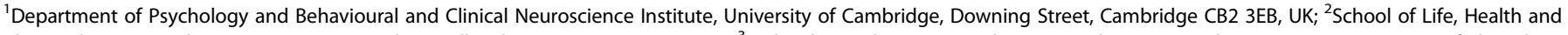

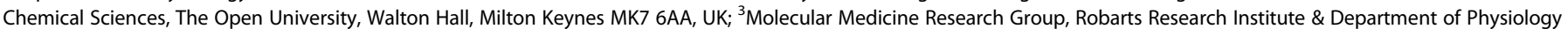

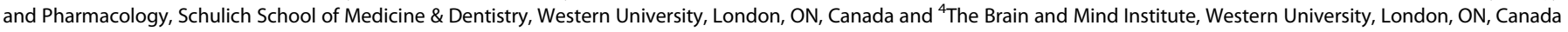
Correspondence: Jonathan M. Hailwood (jmh241@cam.ac.uk) 


\begin{tabular}{|c|c|c|c|c|c|}
\hline \multirow{2}{*}{$\begin{array}{l}\text { Experimental } \\
\text { procedures }\end{array}$} & $\begin{array}{l}\text { Prefeeding } \\
\text { Scopolamine }\end{array}$ & & $\begin{array}{l}\text { Food Consumption } \\
\text { Scopolamine Biperiden }\end{array}$ & & $\begin{array}{l}\text { Progressive ratio } \\
\text { Scopolamine Biperiden }\end{array}$ \\
\hline & & & $\begin{array}{l}\text { Extinction }(n=14) \\
\text { Biperiden }\end{array}$ & & \\
\hline
\end{tabular}

antagonists and attenuated by $m A C h R$ agonists $[22,23]$. These effects upon DA function may be modulated by the M1 receptor subtype [24-26]. Taken together, these studies suggest that muscarinic receptors may be a novel target for treatment of motivational-related disruptions. As antagonism of mAChRs facilitates DA function, it could be hypothesised that blockade of these receptors would facilitate effort-based behaviour. In line with this, administration of a nonselective $m A C h R$ agonist into the nucleus accumbens impairs ERC performance, through shifting behaviour to the lower-effort freely available reward option [27]. Furthermore, this shift was prevented by co-administration of the nonselective mAChR antagonist scopolamine. This study implicates muscarinic receptors in effort-based behaviour. However, it is not known if mAChR antagonists can facilitate effort-based behaviour in otherwise intact rodents. Moreover, the influence of mAChR subtypes on effort-based behaviour is also unknown.

Presently, we aimed to examine the effects of mAChR antagonism on effort exertion in mice. We, therefore, tested the effects of systemic administration of several muscarinic receptor antagonists on touchscreen PR performance $[28,29]$ including the non-specific mAChR antagonist scopolamine and the preferential antagonists biperiden (M1) and tropicamide (M4) to probe the role of distinct receptor subtypes. Additionally telenzepine, a M1 antagonist that does not effectively cross the blood-brain barrier, but is still able to produce peripheral effects [30,31], was used to examine potential peripherally mediated effects on PR performance. Subsequently the effects of biperiden and scopolamine were tested on a number of control tasks to examine the behavioural mechanisms underlying the changes in PR performance, as in previous reports [15]. Finally, we tested the effects of mAChR antagonism on a model of antipsychotic-induced amotivation [14].

\section{MATERIALS AND METHODS}

Animals

Eighty male C57BL/6 mice (Charles River Laboratories, Margate, UK) were involved in this study, divided into five cohorts $(n=16$ each, Table 1). Mice were 6-8-weeks-old at the start of the study and group housed (four per cage) in a temperature and light controlled facility (lights on 1900-0700). Mice were placed on a schedule of controlled feeding and maintained at no $<85 \%$ of their free-feeding weight. Water was available ad libitum throughout. All behavioural testing took place 5-7 days/week during the animals' dark phase. Two mice failed to complete the pretraining procedure and were removed from the study. Another mouse was culled due to ill-health part way through the study. All experiments were conducted in accordance with the Animals (Scientific Procedures) Act 1986 Amendment Regulations 2012 following ethical review by the University of Cambridge Animal Welfare and Ethical Review Body (AWERB).

\section{Apparatus}

All testing took place in standard mouse Bussey-Saksida touchscreen chambers (Campden Instruments Ltd, Loughborough, UK), described in detail elsewhere [28, see Supplementary Materials and Methods]. Behaviour was reinforced with strawberry milkshake (Yazoo ${ }^{\circledR}$; Friesland Campina UK, Horsham, UK).

\section{Progressive ratio procedure}

The PR procedure was identical to the procedures outlined previously [28, see Supplementary Materials and Methods]. Mice were trained to respond on a linear $+4 \mathrm{PR}$ schedule with response requirements of $1,5,9,13,17$ etc. that was reinforced with $20 \mu \mathrm{L}$ of milkshake. If no response was made to the touchscreen within $300 \mathrm{~s}$, sessions were terminated, otherwise sessions ended after $60 \mathrm{~min}$.

Fixed ratio procedure

Fixed ratio-5 (FR5) testing was used to test for any changes in satiety/motor output. During FR5 testing, five responses were required for each reward. Sessions were terminated at 60-min.

Food consumption procedure

The milkshake consumption test took place within the touchscreen chambers. Mice were given 60 -min of free access to milkshake, which was placed within a small bowl that was fixed to the floor of the chamber. The bowls were weighed before and after the session to determine the quantity of milkshake consumed.

\section{Prefeeding procedure}

The prefeeding procedure involved giving mice 60-min free access to either a bowl of milkshake reinforcer (prefeed) or water (control), within the home cages, prior to PR testing. Subsequently, the bowls were removed, and the drug administered. Animals had no further access to the bowls prior to PR testing. All mice received both vehicle and drug following prefeeding with both water and milkshake (resulting in four experimental conditions per compound).

\section{Extinction procedure}

In this paradigm, the white target screen stimulus was presented; however, responding did not yield reward delivery nor the presentation of reward associated cues such as the stimulus offset tone or the sound of the milkshake pump. Sessions were terminated after 60 -min or following $300 \mathrm{~s}$ without any responses to the touchscreen.

Effort-related choice

During effort-related choice testing [28] two pellets of standard lab chow (approximately $5 \mathrm{~g}$ ) were weighed and scattered on the floor of each touchscreen chamber. Animals were then tested on 

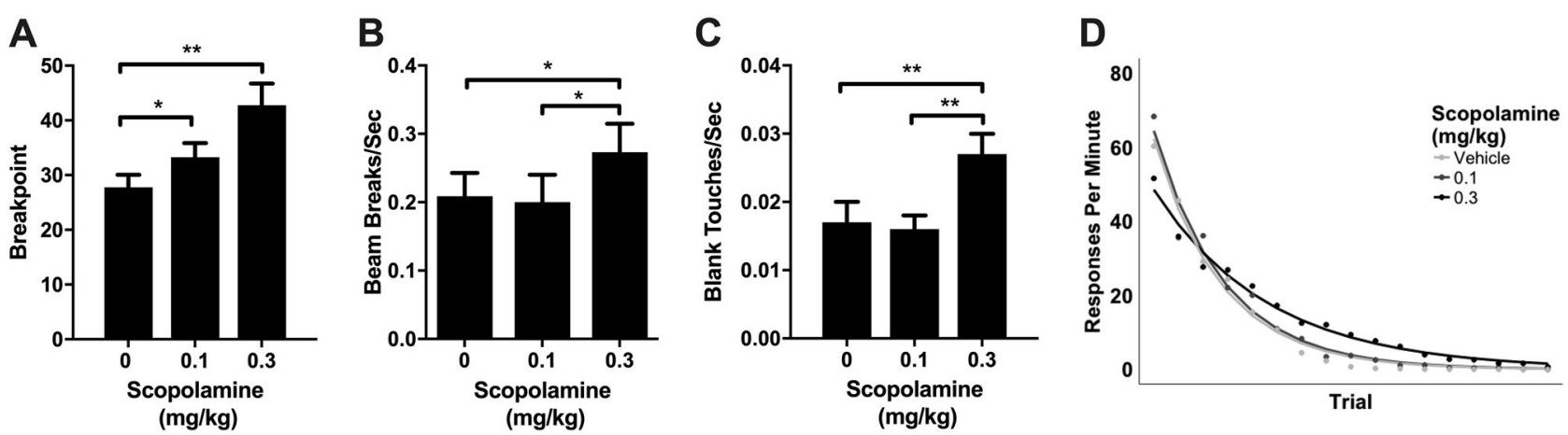

Fig. 1 The effects of systemic scopolamine upon PR performance. a Scopolamine significantly enhances breakpoint. Scopolamine increases measures of general activity including $\mathbf{b}$ the rate of IR beam breaks and $\mathbf{c}$ non-target (blank) screen touches. $\mathbf{d}$ Scopolamine does not affect response rates. Error bars represent SEM. ${ }^{*} p<0.05 ;{ }^{* *} p<0.01$

the FR5 schedule for 60-min. Following testing, the remaining chow (including spillage) was weighed to calculate consumption.

Behavioural measures

The primary outcome measure was breakpoint, defined as the number of stimulus responses emitted in the last successfully completed trial of a session. Additional parameters included postreinforcement pause (PRP), the time between magazine exit following reward delivery and the subsequent screen target response. Additional behavioural measures were used to examine drug-induced changes in non-specific activity [28]. The number of infra-red (IR) beam breaks made per second and the number of non-target (blank) screen touches made per second were used as measures of general locomotor activity.

Response bout analysis defined bouts as consecutive touchscreen target responses separated by no more than $5 \mathrm{~s}$. The mean number of responses in a bout was taken to represent a bout length. Following response bout completion, the pause until the subsequent target response was calculated. The response bout length and inter-bout pause were taken as measures of motoric integrity and motivational output respectively [32]. Only voluntarily terminated bouts were analysed and PRPs excluded from the bout analysis. Analysis of response rates involved fitting an equation to the within-session decline in the rate of responding (lever-press/s, see Supplementary Materials and Methods). This allowed for estimation of the predicted peak response rate and decay rate parameters, providing measures of motoric integrity and the excitatory effect of reinforcers on behaviour respectively [33]. Analysis of response rates and response bouts was not performed on ERC data due to the frequent breaks in touchscreen responding when the mice were consuming lab chow. Additionally, due to the low number of responses made by a number of animals following prefeeding, analysis of response patterns was also not performed here.

\section{Drugs}

With the exception of haloperidol, all compounds were dissolved in physiological saline and administered via intraperitoneal injections at a volume of $10 \mathrm{~mL} / \mathrm{kg}, 30$-min prior to testing. The following doses were tested: Scopolamine hydrobromide (Biotechne, Abingdon, UK): 0.1 and $0.3 \mathrm{mg} / \mathrm{kg}$; biperiden hydrochloride (Sigma-Aldrich, Dorset, UK): 1 and $3 \mathrm{mg} / \mathrm{kg}$; telenzepine dihydrochloride (Bio-techne, Abingdon, UK): 3 and $10 \mathrm{mg} / \mathrm{kg}$; tropicamide (Bio-techne, Abingdon, UK): $20 \mathrm{mg} / \mathrm{kg}$ and amphetamine (Sigma-Aldrich, Dorset, UK): 0.1 and $1 \mathrm{mg} / \mathrm{kg}$. When applied in combination, amphetamine and biperiden were coadministered in the same syringe to reduce the number of injections needed. During the haloperidol reversal studies $0.1 \mathrm{mg} /$ $\mathrm{kg}$ haloperidol (Bio-techne, Abingdon, UK) was dissolved in $0.2 \%$ tartaric acid and administered 40 -min prior to testing. $0.2 \%$ tartaric acid was also administered in the vehicle only condition. Scopolamine $(0.3 \mathrm{mg} / \mathrm{kg})$, biperiden $(3 \mathrm{mg} / \mathrm{kg})$ or saline were administered 10 min later. All drug conditions were administered in a pseudo-random order such that equal numbers of animals received each dose on any given test day.

Statistical analysis

Table 1 outlines the experimental procedures undertaken by each cohort of mice. All drugs were administered via within-subject designs. Statistical analyses were conducted with SPSS 23.0 (IBM Corp, Armonk, NY, US) and the R software package [34]. Graphs were produced using Prism (GraphPad, La Jolla, CA, USA) and the ggplot2 package in $\mathrm{R}$ [35]. Any data points that were greater than two standard deviations from the mean were removed as outliers. Repeated measures ANOVAs were used to analyse the results of all Latin square designs. When violations of sphericity were detected, the Greenhouse-Geisser correction was applied. For significant results, effect sizes were calculated as partial eta squared $\left(\eta^{2}\right)$ values. All post hoc testing was Bonferroni corrected. Cross-over designs were analysed with paired $t$-tests.

\section{RESULTS}

Scopolamine facilitates PR performance and increases non-specific locomotor activity

Figure 1a shows that breakpoint was significantly enhanced by scopolamine $\left(F(1.37,20.56)=9.957, p<0.001\right.$; partial $\left.\eta^{2}=0.399\right)$. Both doses significantly increased breakpoint relative to vehicle $(p$ $<0.05)$. Scopolamine did not affect PRPs $(F(1.40,21.06)=1.331, p$ $=0.279$ ). Figures $1 \mathrm{~b}, \mathrm{c}$ show the effect of scopolamine on activity levels. Scopolamine increased the rate of IR beam breaks $(F(2,30)$ $=5.562, p<0.01$; partial $\eta^{2}=0.284$; Fig. $\left.1 \mathrm{~b}\right) .0 .3 \mathrm{mg} / \mathrm{kg}$ increased IR beam breaks relative to vehicle and $0.1 \mathrm{mg} / \mathrm{kg} \quad(p<0.05)$. Scopolamine also increased the rate of non-target responses ( $F$ $(2,30)=10.12, p<0.001$; partial $\eta^{2}=0.403$; Fig. $\left.1 c\right)$. Non-target responses were elevated following $0.3 \mathrm{mg} / \mathrm{kg}$ relative to both vehicle and $0.1 \mathrm{mg} / \mathrm{kg}(p<0.01)$. In contrast, as seen in Fig. $1 \mathrm{~d}$, scopolamine did not affect response rates (peak response: $(F$ $(1.33,19.89)=1.71, p=0.209)$; decay rate: $(F(2,30)=2.671, p=$ $0.086)$ ). Scopolamine also did not affect response bout length ( $F$ $(2,30)=.229, p=0.796)$. There was, however, a significant effect on the duration of pausing between response bouts $(F(2,30)=$ 4.775, $p<0.05$; partial $\eta^{2}=0.241$ ). Pausing between bouts was significantly shorter following $0.3 \mathrm{mg} / \mathrm{kg}$ scopolamine compared to the $0.1 \mathrm{mg} / \mathrm{kg}$ condition $(p<0.01)$. Supplementary measures are available in Table S1. These data indicate that antagonism of mAChRs can increase effort expenditure, as indexed by PR breakpoint. 
A

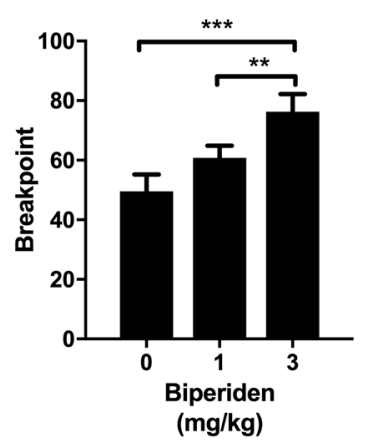

$E$

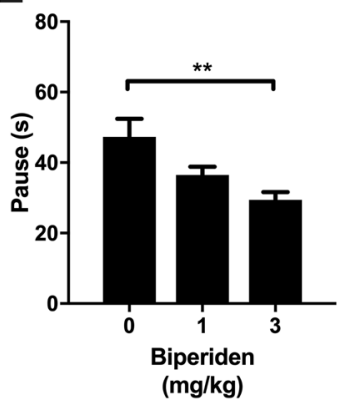

B

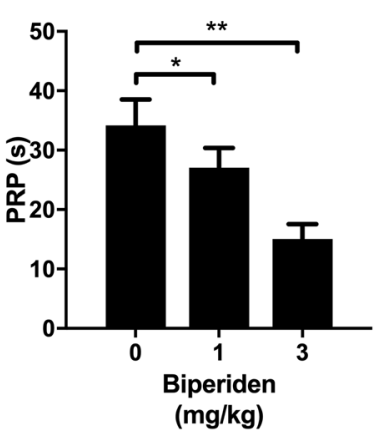

$\mathbf{F}$

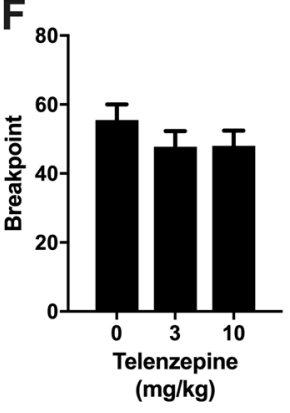

C

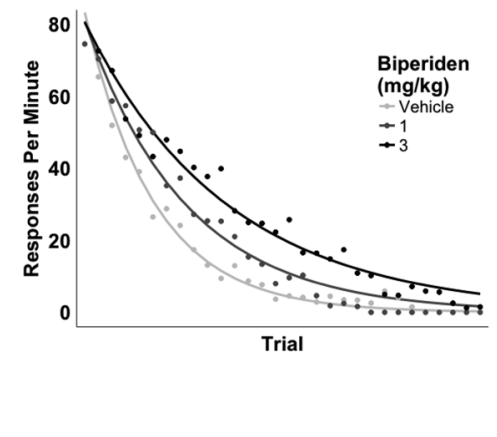

G

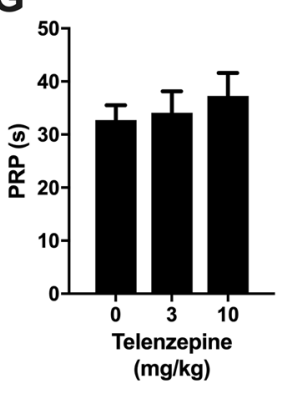

H

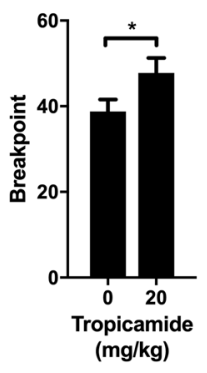

D

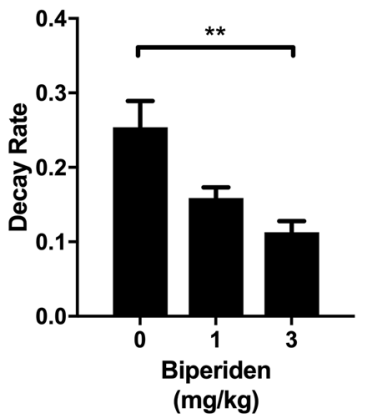

I

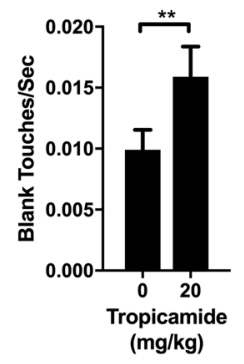

Fig. 2 The effects of systemic subtype-selective muscarinic receptor antagonists, biperiden (M1, a-e), telenzepine (M1, $\mathbf{f}-\mathbf{g}$ ) and tropicamide $(\mathrm{M} 4, \mathbf{h}, \mathbf{i})$ on PR performance. a Biperiden significantly increases breakpoint. $\mathbf{b}$ The duration of post-reinforcement pausing is reduced by biperiden administration. c Biperiden significantly affects response rates. d The rate of decay in responding is significantly reduced by biperiden. e Biperiden significantly reduces the pausing between response bouts. f Telenzepine has no effect on PR breakpoints. $\mathbf{g}$ Telenzepine does not affect the duration of post-reinforcement pausing. Tropicamide significantly increases both $\mathbf{h}$ breakpoint and $\mathbf{i}$ nontarget screen responses. Error bars represent SEM. ${ }^{*} p<0.05 ;{ }^{* *} p<0.01 ;{ }^{* * *} p<0.001$

Biperiden enhances PR performance without affecting general activity levels

Figure $2 \mathrm{a}$ shows breakpoint was significantly increased by biperiden $\left(F(2,30)=18.168, p<0.001\right.$; partial $\left.\eta^{2}=0.548\right) .3 \mathrm{mg} / \mathrm{kg}$ increased breakpoint compared to both vehicle and $1 \mathrm{mg} / \mathrm{kg}$ (both $p<0.01$ ). Biperiden, as shown in Fig. $2 \mathrm{~b}$, also significantly reduced PRPs $\left(F(2,30)=8.366, p<0.01\right.$; partial $\left.\eta^{2}=0.358\right)$. PRPs were significantly shorter following $3 \mathrm{mg} / \mathrm{kg}$ relative to both other conditions $(p<0.05)$. In contrast, neither the rate of IR beam breaks $(F(2,30)=0.927, p=0.407)$, nor the rate of non-target screen touches $(F(1.23,18.48)=1.266, p=0.286)$ were significantly affected.

Biperiden also affected response rates (Fig. 2c). The predicted peak response rate was not significantly affected by biperiden $(F$ $(1.35,20.23)=2.05, p=0.146)$. However, biperiden significantly reduced the response decay rate $(F(2,30)=9.576, p<0.01$, partial $\eta^{2}=0.390$; Fig. 2d). $0.3 \mathrm{mg} / \mathrm{kg}$ biperiden significantly reduced decay rate, relative to the vehicle condition $(p<0.01)$. Biperiden did not significantly affect the mean length of completed bouts $(F$ $(1.480,22.203)=0.515, p=0.551)$. However, biperiden reduced the length of pausing between response bouts $(F(1.295,19.423)=$ $9.682 p<0.01$; partial $\eta^{2}=0.392$; Fig. 2e). Three milligram per kilogram biperiden significantly reduced pausing between bouts relative to vehicle $(p<0.01)$. Supplementary measures are available in Table S1. Taken together, biperiden facilitated a number of measures of motivated behaviour without significantly affecting measures of general activity.

Telenzepine does not affect PR performance

As a control for potential peripheral effects, the M1 receptor antagonist telenzepine, reported to have relatively poor brain penetrance [30,31], was administered prior to PR performance. As seen in Fig. 2f, g, telenzepine affected neither breakpoint $(F(2,30)$
$=2.772, p=0.079)$ nor PRPs $(F(2,30)=0.624, p=0.543)$. Neither the rate of IR beam breaks $(F(2,30)=1.617, p=0.215)$, nor the rate of blank touches were affected $(F(2,30)=0.503, p=0.610)$. Response patterns were also unaffected (predicted peak response: $(F(2,30)=0.172, p=0.843)$; decay rate: $(F(1.28,19.17)=0.595, p=$ 0.558 ; bout length: $(F(2,30)=0.432, p=0.654)$; pausing between bouts: $(F(1.452,20.328)=0.328, p=0.655))$. These data demonstrate that telenzepine has no effect on motivated behaviour.

Tropicamide facilitates PR performance and increases some measures of activity

The effects of scopolamine on PR may also have been driven in part by the M4 receptor. Therefore, the preferential M4-receptor antagonist tropicamide was administered prior to PR testing. Tropicamide, as shown in Fig. $2 \mathrm{~h}$, significantly increased breakpoint $(t(15)=2.218, p<0.05)$; however, there was also an increase in non-target screen responses $(t(15)=3.153, p<0.01$; Fig. 2i). Tropicamide did not significantly affect either the length of PRPs ( $t$ $(15)=1.011, p=0.328)$ or the rate of IR beam breaks $(t(15)=$ $0.567, p=0.579$ ). Tropicamide also had no effect on the pattern of responding (predicted peak response rate: $(t(15)=0.507, p=$ $0.619)$; decay rate: $(t(15)=1.393, p=0.184)$; bout length: $(t(15)=$ $1.856, p=0.083)$; pausing between bouts; $(t(15)=0.228, p=$ 0.823)). Supplementary measures are available in Table S1. These results suggest that antagonism of M4 receptors may facilitate PR performance through an enhancement in non-specific activity.

Scopolamine and biperiden do not affect performance on an FR5 schedule or milkshake consumption

Scopolamine and biperiden were tested on an FR5 schedule to detect any changes in satiety/motor fatigue that may occur within a session [36]. Drug administration did not significantly affect either the number of trials completed $(F(2,28)=2.180, p=0.132$; 
Fig. S1A). There was however, a significant effect of drug administration on the duration of the mean PRP $(F(2,28)=4.678$, $p<0.05$; partial eta squared $=0.250$ ). The mean PRP was shortened following biperiden administration compared to scopolamine $(p<0.01)$, but not compared to vehicle $(p=0.15)$. There was also an effect of drug on the rate of IR beam breaks ( $F$ $(2,28)=3.920, p<0.05$; Fig. S1B). Scopolamine again significantly increased the rate of IR beam breaks relative to vehicle $(p<0.05)$. Drug administration did not significantly affect the rate of nontarget screen responses $(F(2,28)=0.009, p=0.991)$. Response rates, an index of satiety [33] were also unaffected (Fig. S1C). Neither the predicted peak response rate $(F(2,28)=0.180, p=$ $0.836 ;)$, nor the decay in response rate $(F(2,28)=0.958, p=0.396)$ were affected by drug administration. The mean response bout length was not affected by drug administration $(F(2,28)=0.317, p$ $=0.731)$. However, there was a significant drug effect on the mean inter-bout pause $\left(F(2,28)=5.286, p<0.05\right.$, partial $\left.\eta^{2}=0.274\right)$. Biperiden significantly reduced the mean pause compared to vehicle $(p<0.05)$. No other comparisons were significant. Drug administration also produced no effect on 60-min milkshake consumption $(F(2,28)=1.388, p=0.266$; Fig. S1D).

Effects of biperiden and scopolamine are reduced in partially satiated mice

The effects of scopolamine and biperiden were tested following prefeeding to assess whether their effects were dependent on reinforcer value [37]. Scopolamine increased $(F(1,15)=108.182, p$ $<0.001$; partial $\left.\eta^{2}=0.878\right)$ and prefeeding decreased breakpoint $\left(F(1,15)=49.903, p<0.001\right.$; partial $\eta^{2}=0.769 ;$ Fig. S1E). There was also a significant drug xprefeeding interaction on breakpoint $(F$ $(1,15)=16.529, p<0.01$; partial $\left.\eta^{2}=0.524\right)$. However, scopolamine increased breakpoint following both prefeeding with water $(p<$ $0.001)$ as well as milkshake $(p<0.05)$. Biperiden also significantly increased breakpoint $\left(F(1,13)=10.161, p<0.01\right.$; partial $\eta^{2}=0.439$; Fig. S1F); whereas, prefeeding reduced breakpoint $(F(1,13)=$ 48.481, $p<0.001$; partial $\left.\eta^{2}=0.789\right)$. There was a significant biperidenxprefeeding interaction $(F(1,13)=4.875, p<0.05$; partial $\left.\eta^{2}=0.273\right)$. Unlike scopolamine, biperiden only significantly increased breakpoints following prefeeding with water $(p<0.01)$, and not milkshake $(p=0.211)$. Further measures of PR performance are available in Table S2. Therefore, the effects of both drugs on breakpoints were substantially reduced following prefeeding.

\section{Biperiden does not affect extinction}

The previous results suggest biperiden enhances PR performance. It is possible that these effects may have been driven by an increase in perseverative-like responding to the touchscreen stimulus in the absence of reinforcement. Therefore, the effects of biperiden on responding were evaluated in extinction conditions under which the reinforcer is absent. One animal was removed following an outlier analysis. Biperiden did not affect the total number of target touches $(t(12)=1.773, p=0.102$, Fig. S1G). Neither the predicted peak response rate $(t(12)=1.139, p=0.277)$ nor the decay rate $(t(12)=1.808, p=0.096$; Fig. S1H-I) were significantly affected by biperiden. Supplementary behavioural measures are available in Table S3.

Biperiden facilitates the effects of amphetamine upon PR performance

In order to examine whether biperiden interacts with dopaminergic function we investigated potential faciliatory effects of biperiden on PR performance in combination with the indirect catecholamine agonist d-amphetamine. Sub-effective and effective doses of amphetamine [0.1 and $1 \mathrm{mg} / \mathrm{kg}$ respectively, 28] were administered in isolation and in combination with two subeffective doses of biperiden $(0.3$ and $1 \mathrm{mg} / \mathrm{kg})$, which were also administered alone. Figure $3 a$ shows drug administration significantly affected breakpoint $(F(3.016,42.227)=14.093, p<$ 0.001 ; partial $\eta^{2}=0.516$ ). One milligram per kilogram amphetamine increased breakpoint relative to vehicle $(p<0.01)$. In combination with the sub-effective $1 \mathrm{mg} / \mathrm{kg}$ biperiden, amphetamine $(1 \mathrm{mg} / \mathrm{kg})$ had an additive effect to increase breakpoint relative to all other conditions (all $p<.05$ ). No other doses or combination significantly affected breakpoint relative to vehicle.

Figure $3 \mathrm{~b}$ shows that there was also an effect of drug on the rate of IR beam breaks, $(F(1.987,27.696)=11.337, p<0.001$; partial $\left.\eta^{2}=0.447\right)$. Amphetamine $(1 \mathrm{mg} / \mathrm{kg})$ increased beam breaks relative to vehicle $(p<0.05)$. The high dose biperiden/amphetamine combination increased beam breaks relative to vehicle $(p<$ $0.05)$; however, this combination failed to increase the rate of beam breaks $(p>0.05)$ relative to $1 \mathrm{mg} / \mathrm{kg}$ amphetamine alone. Supplementary behavioural measures are available in Table S4.

Biperiden rescues a haloperidol-induced deficit in PR and ERC performance

Biperiden, and scopolamine as a positive comparison, were tested on PR and effort-related choice (ERC) following pre-treatment with the dopamine D2 antagonist haloperidol. Figure $3 \mathrm{c}$ shows that during PR testing, drug administration significantly affected breakpoints $\left(F(3,45)=14.680, p<0.001\right.$; partial $\left.\eta^{2}=0.495\right)$. Haloperidol significantly reduced breakpoint compared to vehicle $(p<$ $0.001)$, whereas administration of scopolamine $(p<0.05)$ and biperiden $(p<0.01)$ successfully reversed this deficit. When tested on ERC, there was an effect of drug on the number of trials completed $\left(F(3,45)=10.386, p<0.001\right.$; partial $\eta^{2}=0.409$; Fig. $\left.3 d\right)$. Figure $3 d$ shows that haloperidol significantly reduced the number of trials completed $(p<0.01)$. Biperiden $(p<0.01)$, but not scopolamine was able to increase trials completed following haloperidol. There was also an effect of drug on chow consumption $\left(F(3,45)=4.861, p<0.01\right.$; partial $\eta^{2}=0.245$; Fig. 3e). Both biperiden and scopolamine (both $p<0.05$ ) reduced chow consumption following haloperidol administration. Additional measures of performance are available in Tables S5 and S6.

\section{DISCUSSION}

Lack of motivation is a substantial clinical problem with few effective treatments. Preclinical identification and characterisation of novel mechanistic targets is a key step in the development of new therapeutic interventions. Table 2 outlines the main findings of the present experiments. Scopolamine, a nonselective mAChR antagonist facilitated PR breakpoints, but also increased measures of locomotor activity. The present results also indicate that targeting the M1 mAChR with biperiden can facilitate PR performance in the absence of changes in locomotor activity. Furthermore, this compound enhanced the behavioural consequences of amphetamine administration and attenuated the behavioural deficits induced by haloperidol on effort-based behaviour. These findings suggest that targeting the $M 1$ receptor subtype in particular may represent a novel approach for the treatment of disrupted motivation.

PR schedules are widely used as preclinical assays of motivation. In rodents, PR schedules have previously been administered via lever or nose-poke equipped operant systems, with the touchscreen-based equivalent only recently characterised $[28,33$, 36]. While the operant schedules themselves are equivalent, the mode of operant responding (engaging with a physical manipulanda versus a touchscreen stimulus) differs, which could in turn impact performance, with increased physical response demands known to reduce operant performance $[38,39]$. However, in spite of less physical effort being needed to respond to a touchscreen stimulus when compared to a typical manipulanda, measures of touchscreen PR performance are consistently lower relative to leverbased systems [40]. This suggests that some non-physical aspect of effort is greater when PR involves touchscreen responding. 
A

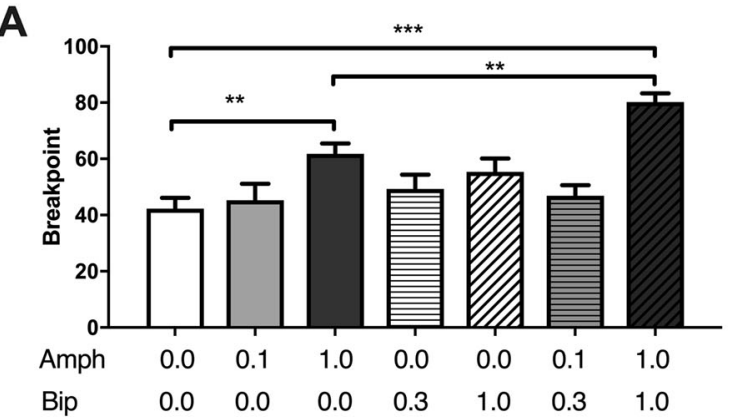

B

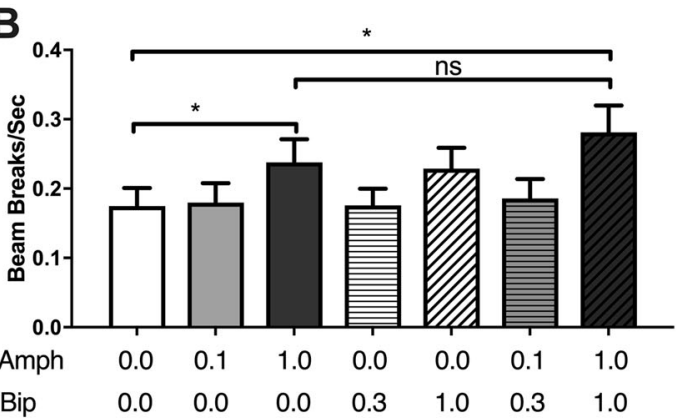

C

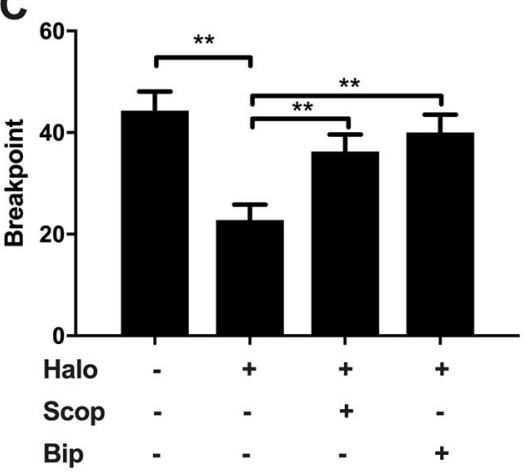

D

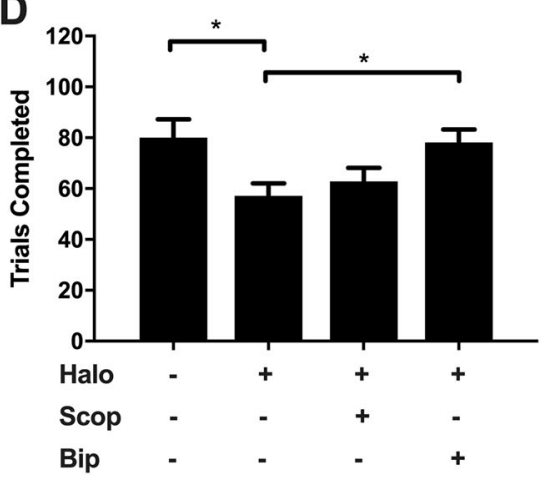

E

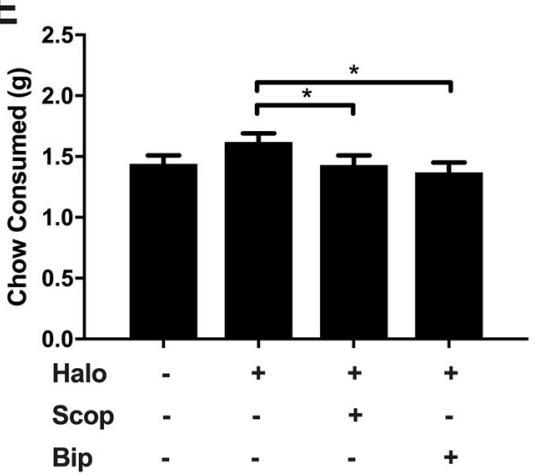

Fig. 3 Biperiden facilitates the behavioural effects of amphetamine on PR performance (a, $\mathbf{b})$ and the effectiveness of scopolamine and biperiden in reversing a haloperidol-induced deficit in PR (c) and ERC performance (d, e). a The dose of amphetamine is represented by the graph fill, whereas the dose of biperiden is indicated by the graph pattern. Biperiden facilitates the enhancement in breakpoints caused by amphetamine but does not affect breakpoint when administered in isolation. $\mathbf{b}$ One milligram per kilogram biperiden does not enhance the general effect of amphetamine on IR beam breaks. c Scopolamine and biperiden successfully reverse a haloperidol-induced deficit on PR breakpoint. d Biperiden, but not scopolamine reverses a haloperidol-induced deficit on the trials completed in an ERC task. e Both scopolamine and biperiden reduce the chow consumed during ERC testing. $\mathbf{a}, \mathbf{b}$ Amph: amphetamine; Bip: biperiden; all doses in mg/kg c-e Halo: haloperidol $0.1 \mathrm{mg} / \mathrm{kg}$ Scop: Scopolamine $0.3 \mathrm{mg} / \mathrm{kg}$ Bip: biperiden $3 \mathrm{mg} / \mathrm{kg}$

\begin{tabular}{|ll|}
\hline Table 2. Summary of the main behavioural effects following systemic administration of each muscarinic receptor antagonist \\
\hline Biperiden & Effect on behaviour \\
& Facilitates multiple measures of motivated behaviour \\
& Does not increase locomotor activity or interfere with satiety/appetite \\
& Effects are dependent on reinforcer value and do not occur in the absence of reinforcement \\
& Facilitates the effects of amphetamine on motivated behaviour \\
& Reverses the motivational deficit induced by haloperidol on PR and ERC performance \\
Scopolamine & Facilitates motivated behaviour; however, also increases general activity \\
& Does not interfere with satiety/appetitive processes \\
& Effects are largely dependent on reinforcer value \\
& Reverses the motivational deficit induced by haloperidol on PR but not on ERC performance \\
Tropicamide & Facilitates PR performance; however, also increases general activity \\
Telenzepine & No effect on motivated behaviour
\end{tabular}

While the use of a touchscreen instead of a manipulanda in PR yields reduced overall performance, touchscreen and nontouchscreen PR schedules exhibit similar sensitivity for detecting changes in performance due to pharmacological manipulations or alterations in reinforcer value $[38,40]$. Furthermore, the present results suggest haloperidol produces a similar reduction in breakpoint $(\sim 50 \%)$ to previous lever-based reports using the same dose [41]. Altogether, this suggests that the touchscreen PR schedule used presently is appropriate for the measurement of effort-based behaviour.

This study also demonstrated the benefit of evaluating multiple measures of PR performance, in line with previous reports [33, 42].
Although scopolamine, biperiden and tropicamide all facilitated PR breakpoint, detailed behavioural analysis revealed a number of differences in the profile of each compound. Biperiden produced relatively selective effects on motivated behaviour, increasing breakpoint and decreasing PRP. Alongside increases in activity, neither scopolamine nor tropicamide significantly affected PRP. Similar effects were observed on response rates, where the rate of decay may reflect the excitatory influence of reinforcers on subsequent responding [33]. Only biperiden reduced the rate of decay in responding. These results suggest that biperiden increased task engagement in mice, attenuating the effects of increasing work requirements on response rates as well as 
pausing. In contrast, neither scopolamine nor tropicamide significantly affected response rates, suggesting the effects of these compounds may be more attributable to non-specific changes in behaviour. There were also differences observed when examining pausing prior to reinforcement. Operant responding is characterised by bouts of responding separated by brief pauses [43]. The refractory pausing between bouts provides a measure of an animal's motivational state, whereas bout length may index motoric function [32]. Such quantitative measures of PR performance are also associated with phasic dopamine transmission [44]. Biperiden significantly reduced the duration of pausing within ratios, without affecting the length of bouts, suggesting an increase in task engagement in the absence of motoric changes.

In the present study, a sub-effective dose of the M1 antagonist biperiden was able to enhance the effects of amphetamine on PR breakpoint. This suggests that the facilitation of the behavioural effects of amphetamine by nonselective mAChR antagonists in previous studies, was probably due to action at the M1 receptor [e.g., 22, 45, 46]. However, amphetamine also facilitates other neurotransmitter systems including serotonin and in particular noradrenaline [47, 48]. Thus, we used the more selective D2 receptor antagonist haloperidol to model the dopaminergic deficiency found in neuropsychiatric disorders [14, 49]. It should be noted that haloperidol also acts as an antagonist on adrenergic a1 receptors [50], suggesting that an interaction with the noradrenergic system cannot be ruled out. Presently, biperiden reversed the deficit induced by haloperidol on both effort exertion (PR) and effort-based decision making (ERC).

Several previous reports of pharmacological enhancement of effort-based behaviour in rodents have used serotonergic and adenosinergic compounds $[14,15]$. A number of these drug targets have been shown to indirectly modulate dopamine function during behaviour [51, 52]. Several studies have also suggested a link between acetylcholine and dopamine function $[53,54]$. There are also studies implicating muscarinic signalling and dopamine function [55]. The present behavioural effects of biperiden following prefeeding and under extinction conditions are different from those seen following activation of the mesolimbic dopamine system [37], suggesting the present effects of biperiden may occur through a separate pathway. However, in the absence of a direct neurochemical or electrophysiological investigation, the effects of biperiden on dopamine function are unknown.

The present findings indicate that antagonism of $M 1$ receptors may be an effective approach to ameliorating amotivation associated with a number of disorders. Biperiden itself may be a candidate drug for this purpose as it is already approved as an antiparkinsonian treatment, as well as a treatment for the extrapyramidal side effects associated with antipsychotic medication [56]. Indeed, there are reports that biperiden may reduce negative symptoms in schizophrenia [57], although it is unclear whether this is due to effects on motivation, or a consequence of the mood-enhancing effects of biperiden [58]. However, the use of muscarinic receptor antagonists as therapeutic agents should be tempered by the findings that such compounds, including biperiden, can induce cognitive impairments across species [59, 60]. It is possible that cognitive disruptions interfere with the costbenefit processes that govern PR performance, resulting in higher breakpoints. However, if such cognitive disruption was a mediating factor then biperiden should similarly increase responding under extinction conditions, which was not observed. Furthermore, the effective dose of biperiden employed in the present study is lower than that typically needed for significant cognitive impairments $[59,61]$.

Motivational impairments are a particularly detrimental and pernicious symptom common to many neuropsychiatric and neurodegenerative diseases, yet no therapeutic options are currently available. The present results indicate that targeting the $\mathrm{M} 1 \mathrm{mAChR}$, such as through administration of biperiden, can facilitate effort-based behaviour in mice. Furthermore, targeting the $M 1$ receptor subtype can ameliorate the effects of a dopamine receptor antagonist on progressive ratio and effortrelated choice performance and potentiate the effects of amphetamine on PR performance. Biperiden in particular may therefore represent a viable drug for the treatment of disrupted motivation.

\section{FUNDING AND DISCLOSURE}

JMH is funded by a Medical Research Council CASE studentship, in collaboration with Eli Lilly and Co. TWR discloses consultancy with Cambridge Cognition, H.. Lundbeck $\mathrm{A} / \mathrm{S}$, Unilever and Mundipharma and has research grants with $\mathrm{H}$. Lundbeck $\mathrm{A} / \mathrm{S}$ and Shionogi. LMS and TJB consult for Campden Instruments, Ltd. The other authors declare no competing interests.

\section{ADDITIONAL INFORMATION}

Supplementary Information accompanies this paper at (https://doi.org/10.1038/ s41386-018-0281-8).

\section{REFERENCES}

1. Foussias G, Agid O, Fervaha G, Remington G. Negative symptoms of schizophrenia: clinical features, relevance to real world functioning and specificity versus other CNS disorders. Eur Neuropsychopharmacol. 2014;24:693-709.

2. Lanctôt KL, Agüera-Ortiz L, Brodaty H, Francis PT, Geda YE, Ismail Z, et al. Apathy associated with neurocognitive disorders: Recent progress and future directions. Alzheimers Dement. 2017;13:84-100.

3. Ho BC, Nopoulos P, Flaum M, Arndt S, Andreasen NC. Two-year outcome in firstepisode schizophrenia: predictive value of symptoms for quality of life. Am J Psychiatry. 1998;155:1196-201.

4. Strauss GP, Horan WP, Kirkpatrick B, Fischer BA, Keller WR, Miski $P$, et al. Deconstructing negative symptoms of schizophrenia: avolition-apathy and diminished expression clusters predict clinical presentation and functional outcome. J Psychiatr Res. 2013;47:783-90.

5. Fervaha G, Takeuchi H, Lee J, Foussias G, Fletcher PJ, Agid O, et al. Antipsychotics and amotivation. Neuropsychopharmacology. 2015;40:1539-48.

6. Artaloytia JF, Arango C, Lahti A, Sanz J, Pascual A, Cubero P, et al. Negative signs and symptoms secondary to antipsychotics: a double-blind, randomized trial of a single dose of placebo, haloperidol, and risperidone in healthy volunteers. Am J Psychiatry. 2006;163:488-93.

7. Salamone JD, Correa M. The mysterious motivational functions of mesolimbic dopamine. Neuron. 2012;76:470-85.

8. Salamone JD, Steinpreis RE, McCullough LD, Smith P, Grebel D, Mahan K. Haloperidol and nucleus accumbens dopamine depletion suppress lever pressing for food but increase free food consumption in a novel food choice procedure. Psychopharmacol (Berl). 1991;104:515-21.

9. Robbins TW, Everitt BJ. Functional studies of the central catecholamines. Int Rev Neurobiol. 1982;23:303-65.

10. Hodos W. Progressive ratio as a measure of reward strength. Science. 1961;134:943-4.

11. Sokolowski JD, Salamone JD. The role of accumbens dopamine in lever pressing and response allocation: effects of 6-OHDA injected into core and dorsomedial shell. Pharmacol Biochem Behav. 1998:59:557-66.

12. Aberman JE, Ward SJ, Salamone JD. Effects of dopamine antagonists and accumbens dopamine depletions on time-constrained progressive-ratio performance. Pharmacol Biochem Behav. 1998;61:341-8.

13. Poncelet $M$, Chermat $R$, Soubrie $P$, Simon $P$. The progressive ratio schedule as a model for studying the psychomotor stimulant activity of drugs in the rat. Psychopharmacol (Berl). 1983;80:184-9.

14. Farrar AM, Pereira M, Velasco F, Hockemeyer J, Müller CE, Salamone JD. Adenosine $A(2 A)$ receptor antagonism reverses the effects of dopamine receptor antagonism on instrumental output and effort-related choice in the rat: implications for studies of psychomotor slowing. Psychopharmacol (Berl). 2007;191:579-86.

15. Bailey MR, Williamson C, Mezias C, Winiger V, Silver R, Balsam PD, et al. The effects of pharmacological modulation of the serotonin $2 \mathrm{C}$ receptor on goal-directed behavior in mice. Psychopharmacol (Berl). 2016;233:615-24.

16. Salamone JD, Correa M, Yohn S, Lopez Cruz L, San Miguel N, Alatorre L. The pharmacology of effort-related choice behavior: Dopamine, depression, and individual differences. Behav Process. 2016;127:3-17. 
17. Sommer S, Danysz W, Russ H, Valastro B, Flik G, Hauber W. The dopamine reuptake inhibitor MRZ-9547 increases progressive ratio responding in rats. Int J Neuropsychopharmacol. 2014;17:2045-56.

18. Clark AN, Mankikar GD. d-Amphetamine in elderly patients refractory to rehabilitation procedures. J Am Geriatr Soc. 1979;27:174-7.

19. Rosenberg PB, et al. Safety and efficacy of methylphenidate for apathy in Alzheimer's disease: a randomized, placebo-controlled trial. J Clin Psychiatry. 2013;74:810-6.

20. Lieberman JA, Kane JM, Alvir J. Provocative tests with psychostimulant drugs in schizophrenia. Psychopharmacol (Berl). 1987;91:415-33.

21. Felder CC. Muscarinic acetylcholine receptors: signal transduction through multiple effectors. FASEB J. 1995;9:619-25.

22. Carlton PL. Augmentation of the behavioral effects of amphetamine by scopolamine. Psychopharmacologia. 1961;2:377-80.

23. Kaakkola S. Effect of nicotinic and muscarinic drugs on amphetamine- and apomorphine-induced circling behaviour in rats. Acta Pharmacol Toxicol (Copenh). 1981;48:162-7.

24. Stanhope KJ, Mirza NR, Bickerdike MJ, Bright JL, Harrington NR, Hesselink MB, et al. The muscarinic receptor agonist xanomeline has an antipsychotic-like profile in the rat. J Pharmacol Exp Ther. 2001;299:782-92.

25. Gerber DJ, Sotnikova TD, Gainetdinov RR, Huang SY, Caron MG, Tonegawa S. Hyperactivity, elevated dopaminergic transmission, and response to amphetamine in M1 muscarinic acetylcholine receptor-deficient mice. Proc Natl Acad Sci USA. 2001;98:15312-7.

26. Woolley ML, Carter HJ, Gartlon JE, Watson JM, Dawson LA. Attenuation of amphetamine-induced activity by the non-selective muscarinic receptor agonist, xanomeline, is absent in muscarinic M4 receptor knockout mice and attenuated in muscarinic M1 receptor knockout mice. Eur J Pharmacol. 2009:603:147-9.

27. Nunes EJ, Randall PA, Santerre JL, Given AB, Sager TN, Correa M, et al. Differential effects of selective adenosine antagonists on the effort-related impairments induced by dopamine D1 and D2 antagonism. Neuroscience. 2010;170:268-80.

28. Heath CJ, Bussey TJ, Saksida LM. Motivational assessment of mice using the touchscreen operant testing system: effects of dopaminergic drugs. Psychopharmacol (Berl). 2015;232:4043-57.

29. Heath CJ, Phillips BU, Bussey TJ, Saksida LM. Measuring motivation and rewardrelated decision making in the rodent operant touchscreen system. Curr Protoc Neurosci. 2016;74:8.34.1-20.

30. Ichikawa J, Chung YC, Li Z, Dai J, Meltzer HY. Cholinergic modulation of basal and amphetamine-induced dopamine release in rat medial prefrontal cortex and nucleus accumbens. Brain Res. 2002;958:176-84.

31. Pediani JD, Ward RJ, Godin AG, Marsango S, Milligan G. Dynamic regulation of quaternary organization of the M1 muscarinic receptor by subtype-selective antagonist drugs. J Biol Chem. 2016;291:13132-46.

32. Brackney RJ, Cheung THC, Neisewander JL, Sanabria F. The isolation of motivational, motoric, and schedule effects on operant performance: a modeling approach. J Exp Anal Behav. 2011;96:17-38.

33. Phillips BU, Heath CJ, Ossowska Z, Bussey TJ, Saksida LM. Optimisation of cognitive performance in rodent operant (touchscreen) testing: Evaluation and effects of reinforcer strength. Learn Behav. 2017;45:252-62.

34. R Core Team. R: A language and environment for statistical computing. Vienna, Austria; 2017.

35. Wickham H. ggplot2-Elegant graphics for data analysis. New York, NY: Springer New York; 2009.

36. Kim EW, Phillips BU, Heath CJ, Cho SY, Kim H, Sreedharan J, et al. Optimizing reproducibility of operant testing through reinforcer standardization: identification of key nutritional constituents determining reward strength in touchscreens. Mol Brain. 2017;10:31.

37. Boekhoudt L, Wijbrans EC, Man JHK, Luijendijk MCM, de Jong JW, van der Plasse G. Vanderschuren LJMJ, Adan RAH. Enhancing excitability of dopamine neurons promotes motivational behaviour through increased action initiation. Eur Neuropsychopharmacol. 2018;28:171-84.

38. Skjoldager P, Pierre PJ, Mittleman G. Reinforcer Magnitude and Progressive Ratio Responding in the Rat: Effects of Increased Effort, Prefeeding, and Extinction. Learn Motiv. 1993;24:303-43.

39. Alling $K$, Poling $A$. The effects of differing response-force requirements on fixed ratio responding of rats. J Exp Anal Behav. 1995;63:331-46.

40. Hailwood JM, Heath CJ, Robbins TW, Saksida LM, Bussey TJ. Validation and optimisation of a touchscreen progressive ratio test of motivation in male rats. Psychopharmacology (Berl). 2018;235:2739-53.
41. Olarte-Sánchez CM, Valencia-Torres L, Cassaday HJ, Bradshaw CM, Szabadi E. Effects of SKF-83566 and haloperidol on performance on progressive ratio schedules maintained by sucrose and corn oil reinforcement: quantitative analysis using a new model derived from the Mathematical Principles of Reinforcement (MPR). Psychopharmacol (Berl). 2013;230:617-30.

42. Bailey MR, Simpson EH, Balsam PD. Neural substrates underlying effort, time, and risk-based decision making in motivated behavior. Neurobiol Learn Mem. 2016;133:233-56.

43. Shull RL, Gaynor ST, Grimes JA. Response rate viewed as engagement bouts: effects of relative reinforcement and schedule type. J Exp Anal Behav. 2001;75:247-74.

44. Ko D, Wanat MJ. Phasic dopamine transmission reflects initiation vigor and exerted effort in an action- and region-specific manner. J Neurosci. 2016;36:2202-11.

45. Galambos E, Pfeifer AK, György L, Molnár J. Study on the excitation induced by amphetamine, cocaine and alpha-methyltryptamine. Psychopharmacologia. 1967;11:122-9.

46. Barrett RJ, Leith NJ, Ray OS. A behavioral and pharmacological analysis or variables mediating active avoidance behavior in rats. J Comp Physiol Psychol. 1973;82:489-500.

47. Kuczenski R, Segal DS. Effects of methylphenidate on extracellular dopamine, serotonin, and norepinephrine: comparison with amphetamine. J Neurochem. 1997;68:2032-7.

48. Rothman RB, Baumann $\mathrm{MH}$, Dersch CM, Romero DV, Rice $\mathrm{KC}$, Carroll Fl, et al. Amphetamine-type central nervous system stimulants release norepinephrine more potently than they release dopamine and serotonin. Synapse. 2000;39:3241.

49. Mott AM, Nunes EJ, Collins LE, Port RG, Sink KS, Hockemeyer J, et al. The adenosine A2A antagonist MSX-3 reverses the effects of the dopamine antagonist haloperidol on effort-related decision making in a T-maze cost/benefit procedure. Psychopharmacol (Berl). 2009;204:103-12.

50. Minzenberg MJ, Yoon JH. An index of relative central a-adrenergic receptor antagonism by antipsychotic medications. Exp Clin Psychopharmacol. 2011;19:31-9.

51. Nunes EJ, Randall PA, Hart EE, Freeland C, Yohn SE, Baqi Y, et al. Effort-related motivational effects of the VMAT-2 inhibitor tetrabenazine: implications for animal models of the motivational symptoms of depression. J Neurosci. 2013;33:19120-30.

52. Bailey MR, Goldman O, Bello EP, Chohan MO, Jeong N, Winiger V, et al. An interaction between serotonin receptor signaling and dopamine enhances goaldirected vigor and persistence in mice. J Neurosci. 2018;38:2149-62.

53. Threlfell $S$, Clements MA, Khodai $T$, Pienaar IS, Exley R, Wess J, et al. Striatal muscarinic receptors promote activity dependence of dopamine transmission via distinct receptor subtypes on cholinergic interneurons in ventral versus dorsal striatum. J Neurosci. 2010;30:3398-408.

54. Soares-Cunha C, Coimbra B, Domingues AV, Vasconcelos N, Sousa N, Rodrigues AJ. Nucleus accumbens microcircuit underlying D2-MSN-driven increase in motivation. Eneuro. 2018;5:ENEURO.0386-18.2018.

55. Shin JH, Adrover MF, Wess J, Alvarez VA. Muscarinic regulation of dopamine and glutamate transmission in the nucleus accumbens. Proc Natl Acad Sci USA 2015;112:8124-9.

56. Gjerden P, Bramness JG, Slørdal L. The use and potential abuse of anticholinergic antiparkinson drugs in Norway: a pharmacoepidemiological study. $\mathrm{Br} \mathrm{J}$ Clin Pharmacol. 2009;67:228-33.

57. Tandon R, DeQuardo JR, Goodson J, Mann NA, Greden JF. Effect of anticholinergics on positive and negative symptoms in schizophrenia. Psychopharmacol Bull. 1992;28:297-302.

58. Fleischhacker WW, Barnas C, Günther V, Meise U, Stuppäck C, Unterweger B. Mood-altering effects of biperiden in healthy volunteers. J Affect Disord. 1987;12:153-7.

59. Talpos JC, Aerts N, Fellini L, Steckler T. A touch-screen based paired-associates learning (PAL) task for the rat may provide a translatable pharmacological mode of human cognitive impairment. Pharmacol Biochem Behav. 2014;122:97-106.

60. Sambeth A, Riedel WJ, Klinkenberg I, Kähkönen S, Blokland A. Biperiden selec tively induces memory impairment in healthy volunteers: no interaction with citalopram. Psychopharmacol (Berl). 2015;232:1887-97.

61. Malikowska N, Sałat K, Podkowa A. Comparison of pro-amnesic efficacy of scopolamine, biperiden, and phencyclidine by using passive avoidance task in CD-1 mice. J Pharmacol Toxicol Methods. 2017;86:76-80. 